\title{
Pink Purchasing: Interrogating the Soft Power of Japan's Kawaii Consumption
} Shiri Lieber-Milo ${ }^{1}$

\begin{abstract}
In Japan high value and appreciation is ascribed towards anything that features the physical characteristics considered to be kawaii (roughly translated as cute in English), particularly infants. As such, kawaii plays a significant role in Japanese popular consumption culture, especially for female consumers. This paper applies mixed methods, including literature review, questionnaires conducted among 692 Japanese female of varying ages and social status, and interviews with 12 Japanese company female employees to investigate perceived positive affective aspects associated with kawaii products, including their impact on emotional states and behaviour. The cross-sectional study results reveal the importance of kawaii among Japanese women and positive aspects in consuming cute items; for working women, it was found, kawaii products help in dealing with stress and serve as a momentary gateway from the harsh world of everyday life to a romanticized world of one's childhood and for younger women serve as a fashion statement.
\end{abstract}

\section{Keywords}

Consumption, Cute, Japan, Nostalgia, Women, Kawaii

\section{Introduction}

Kawaii (commonly translated to cute in English) aesthetics play a significant role in Japanese popular consumer culture. The aesthetic qualities of kawaii, including the physical characteristics of a rounded face, large eyes, and petite body, stimulate warm and cheerful feelings and increased positivity for the observer (Nittono, 2019a). All of these qualities have established the kawaii genre as a significant and remunerative market segment with a kind of 'soft power.' Marketers have learned that consumers will embrace products that create an atmosphere of warmth and vulnerability (Granot, Alejandro, and Russell 2014). The kawaii design aesthetic has become so common that today it is ubiquitous in the Japanese marketplace, applied via companies' commercial "brand-face" to attract potential customers, embodied in character mascots (Yaru Karya), and promoted by government representatives who use the 
Yaru Karya to convey sincere concern for public welfare (Allison, 2004). The term itself is widely used for describing objects that feature many of the physical attributes of an infant (Burdelski and Mitsuhashi, 2010; Nittono, 2019b).

But why cute design and cute is highly evaluated in Japan?

According to Lieber-Milo and Nittono (2019a) while the feeling toward cuteness and kawaii is probably is a universal psychological experience, Japan has accepted recognize the influential power of cute before other countries. In their words "this special appreciation could potentially be seen as associated with Japan's national characteristics, such as its ethnic homogeneity, its island topography, and its abundance of agricultural and fishery products "(p.5). In a country where daily life is characterized by formality and prescribed behavior, cuteness assumes a powerful source of intimacy in Japan, with the sight of cute things helping to transcend the walls of formality and bring people closer together (May, 2019). In the author's own experience, only after the birth of a son did Japanese strangers' approach and begin talking casually, saying the baby is kawaii and asking to touch and play with him.

Recently, thanks to globalization, the kawaii term has become a well-known word not only in Japan but also abroad (Lieber-Milo and Nittono, 2019b).

As a term, while in English, as in many other languages, the word is typically translated as "cute and pretty", in Japanese, kawaii comprises various meanings, such as sweetness, compassion and helplessness, that can be seen as contradictory to one another (Endō, 2016; Ohkura, 2019).In the words of Nittono (2019b, 141), "the Japanese concept of kawaii has a broader range of meanings in addition to cute". This includes coined adjectives that seem to be antonymous such as ita (painful)-kawaii and kimo (bad feeling)- kawaii.

This paper will focus on how Japanese young and more mature women observe and define the term kawaii, as well as will show the positive emotions engendered by the consumption of kawaii and cute artefacts and related products. 
In a recent publication Nittono (2016) translated the Japanese meaning of kawaii to English based on its definition in The Great Japanese Dictionary 1995 [Nihongo no Daijiten] as describing something attractive and adorable that has a sweet nature and is cherished by many. While it is still not clear when the word first came into use, it is known that the positive associations linked to the meaning of the term rooted in the 11th century book The Pillow Book (Sei Shōnagon, 1002/2011). In her writing author Sei Shōnagon (1002) reveals her deepest thoughts, desires and opinions relating to the aristocratic world of her time. In one of her chapters, entitled 'Pretty Things [Utsukushiki Mono],' she describes the things that are considered, from her point of view, to be beautiful, such as the face of a child, a baby, a small object and a little girl.

Whether the general origins of its meaning date back to the 11 th century or not, presentday kawaii culture took root in the 1970s among young women, who are considered to be the ones who shaped kawaii and enabled it to achieve its current success (Monden, 2015). These young women [in Japanese Shöjo] are girls who are yet unmarried and who act and dress in a girlish or cutesy manner. The kawaii culture has a close relationship to shojo, in which these young girls present themselves as having a sweet, innocent, pure and infantile nature, the same qualities associated with the term kawaii.

This association between young women and kawaii evolved and strengthened during the 1970s through a schoolgirls' handwriting fashion that was often called burikko-ji [fakechild writing]; a writing style that is characterized by its round-shaped letters along with English lettering and cartoon pictures. This trend gained momentum over the years to the point that today, this cursive handwriting is used extensively by publications that aims for a younger audience, such as manga, women's magazines and advertisements (Decatur 2012). Thanks to these young women, since the 1970s this trend has continued to be a dominant element in Japan's social, cultural and financial sectors. 
While until recently the kawaii trend belonged almost exclusively to young women's and children's world culture, in light of Japan's shrinking youth population more and more companies are attempting to expand their consumer target market to other potential consumer groups, such as mature women who still wish to possess kawaii merchandise (Yano 2013). In an attempt to adjust their brand by targeting other age groups, the company Sanrio, for example, has developed a fresh line of products that include adult-oriented goods such as personal electronics and jewellery. The success of these adult-targeted products was reflected by the fact that by 2000, the core Hello Kitty customer-base was mature women between the ages of 18 and 40 (May, 2019). These positive attributes have made it a powerful factor in the sales many consumer products (Lieber-Milo and Nittono, 2019b).

While many previous researchers have focused on the figural characteristics and performance of kawaii goods, the perceived influence of kawaii goods on behavior and emotional states has not yet been thoroughly examined. The study described here aims to identify how kawaii is defined and projected by young and more mature Japanese women, as well as clarifying their attitudes toward kawaii and cute products. To do this the author administered a survey to respondents from two groups: female university students between the ages of 18 and 23 (median age of 21), and more mature women between the ages of 23 and 29 (median age of 27) who had graduated from higher educational institutions and were either married, had children or had jobs.

This cross-sectional survey results showed that kawaii is a well-known, relevant and beloved term for both young and adult Japanese women. The results of the study demonstrated the positive aspects and effects of kawaii products upon consumers; stimulating warm and cheerful feelings, bringing temporary relaxation and happiness that helps in reducing tensions in stressful situations. The results also showed that the sight and consumption of kawaii and 
cute goods elicit positive and nostalgic memories of one's childhood, creating a temporary bridge to a world of relaxation and happiness.

\section{Methodology}

The study is based on both qualitative and quantitative research, including a survey that was distributed to 692 female Japanese respondents of different ages and occupations, and 12 semistructured interviews with female employees from TowerJazz Panasonic Semiconductor Company in Uozu city, Japan. The survey and interview data were analysed to understand how the women respondents defined the concept of kawaii aesthetics, their perceptions towards kawaii merchandise, and perceived attributes.

The survey included 11 questions regarding the participant's knowledge, approach and attitudes towards kawaii goods. The survey consisted of a variety of types of questions, to obtain robust data and to allow study participants to respond fully and sincerely. This included openended questions and quantitative questions, which included dichotomous, ordinal level, interval level scale and Likert scale (e.g. 'strongly agree' to ‘strongly disagree') questions.

The survey was distributed to two age and status groups in two phases over a period of five months (from October 2015 to March 2016): university students between the ages of 18 and 23 $(M d n=27, \mathrm{n}=350)$, and more mature women between the ages of 23 and $29(M d n=27, \mathrm{n}=350)$ who had graduated from higher educational institutions. The first survey was hand-distributed by the researcher to 295 randomly chosen participants from three selected universities in the Kansai region of western Japan: Kyoto University, Osaka University and Doshisha University. These universities were selected due their popularity in the Kansai area (two national universities and one private), as they attract a variety of students from all over Japan, which contributes a broader and deeper perspective to the analysis. As of August 20, 2019, Nikkei Business Publications listed Kyoto, Osaka and Doshisha Universities as the top universities in 
the Kansai area. In addition, the selection of two national universities (Osaka and Kyoto) and a private one (Doshisha) helps in investigating whether students from different types of universities exhibit differing responses toward the kawaii trend .

The second survey was delivered online (Questant survey software), to 47 students and 300 mature women respondents who lived, as with the first survey, in the Kyoto or Osaka metropolitan areas.

\section{Survey Results}

The survey contained a few open-ended questions that allowed respondents to express their own personal opinions and perspectives regarding the term kawaii term and associated behaviour, such as 'Please describe in your own words how you define kawaii and kawaii behavior'. [Anata ga kangaeru 'kawaii' kotoba ya kōdō towa donoyōna monodesu ka? Anata jishin no kotoba de okikase kudasai]. The open-ended question produced a wide spectrum of views regarding kawaii.

The responses of both groups of participants were aggregated and each response was placed in one of five categories: gender [seibetsu], appearance [gaikan], positive qualities [pojitibu na tokusei], negative qualities [negatibu na tokusei] and neither positive nor negative [pojitibu demo negatibudehaarimasen]. The results are presented in Tables 1 and 2 below.

Table 1: 163 young university students' (age range 18-23) response to the question "Please describe in your own words how you define kawaii" (in numbers) 


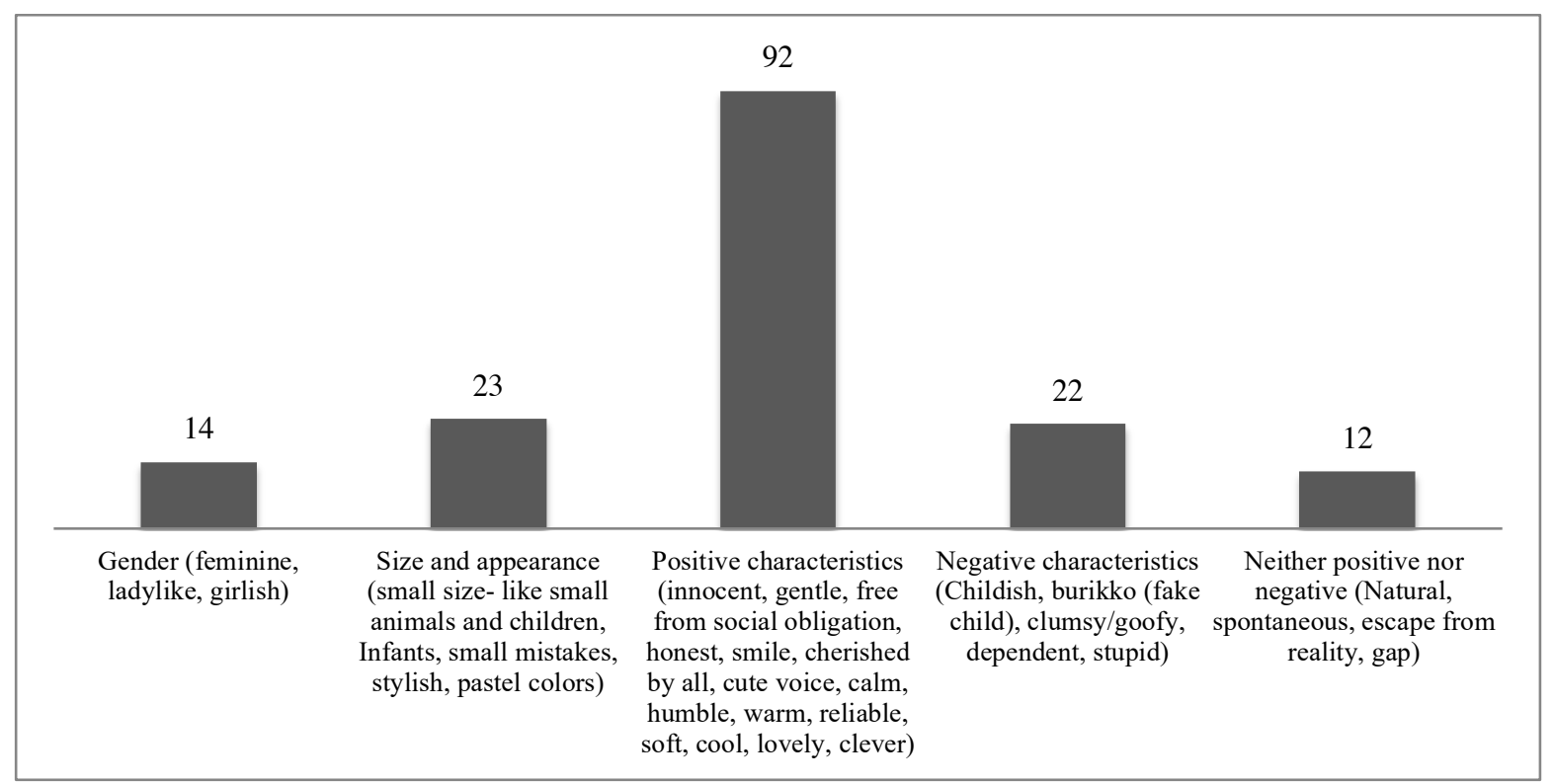

Table 2: 297 more mature women's (age range 23-29) response to the question "Please describe in your own words how you define kawaii" (in numbers)

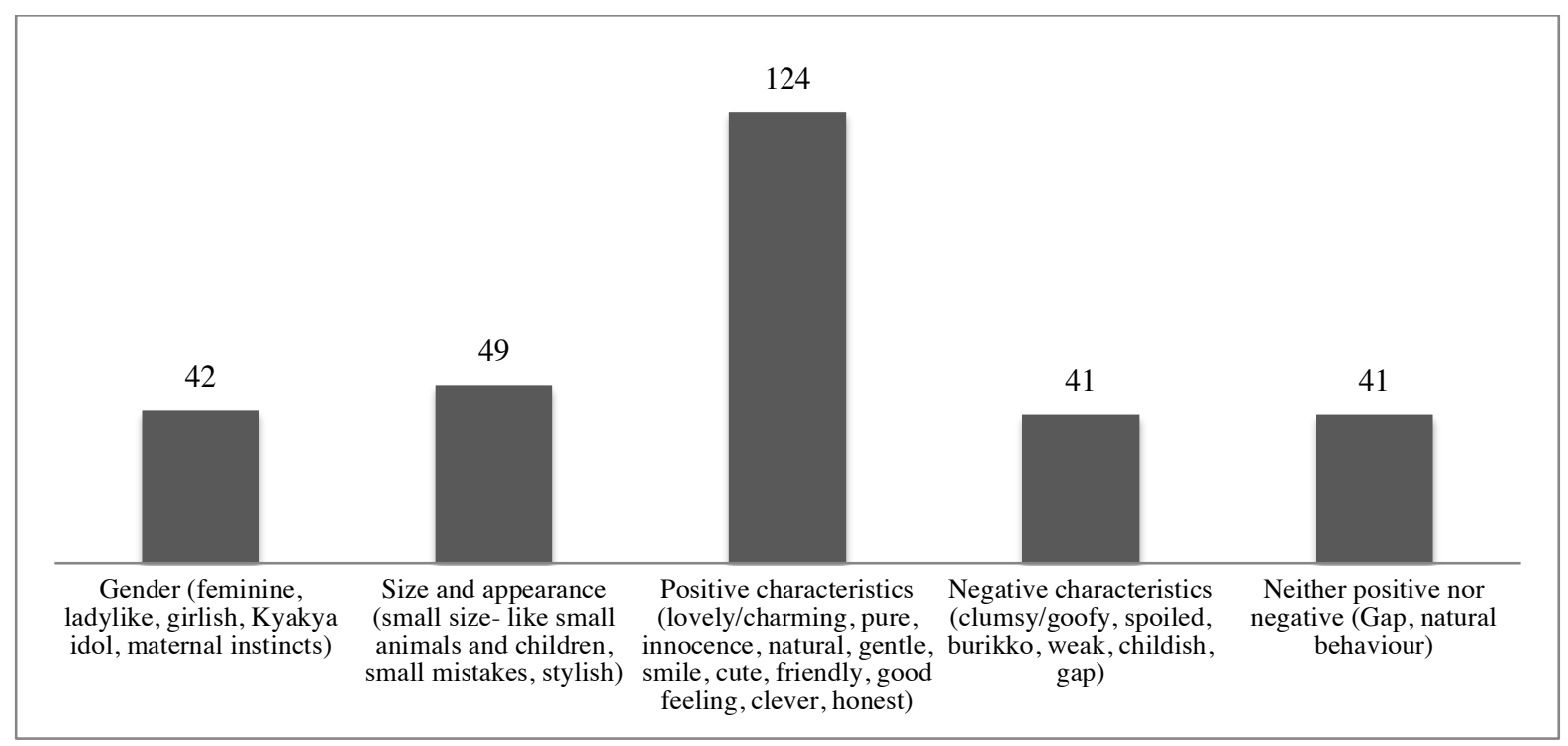

As can seen from the Tables above, both young and mature women defined a kawaii article in the same manner: as something small, soft, round, with pastel colors such as light pink and associated with young animals and humans. These visual features trigger a sympathetic and positive response, hence a high amount of both group respondents $(n=375,54$ per cent $)$ stated 
they 'tend to behave in a friendlier way when observing kawaii articles.' (Question Q5 ${ }^{1}$ ).

Although both groups defined kawaii in the same manner, some differences were found between the groups, where young female students gave more affirmative answers regarding the level of affection toward kawaii commodities than did the mature women. A Mann-Whitney U test indicated that the reported attitude toward kawaii items ${ }^{2}$ was significantly different between the sample of the students $(\mathrm{M}=3.806$, Mean rank $=371.43, \mathrm{n}=340)$ compared to the sample of mature women $(\mathrm{M}=3.566$, Mean rank $=320.31, \mathrm{n}=350), \mathrm{U}=68315, \mathrm{p}<.001(\mathrm{z}=3.53), \mathrm{r}$ $=.134$. The best model to describe the relationship is the inverse one $\left(F(1,673)=20.771, R^{2}=\right.$ $.030, p<.001$, in regards to the linear model $\left.F(1,673)=19.440, R^{2}=.028, p<.001\right)$ as can be viewed in 1 below. Thus we can formulate the following expression: $\mathrm{Q} 4=2.622+(25.012 /$ Age $)$ $+\xi$

Table 3: Model summary and parameter estimates dependent variable: Attitude and affection toward kawaii items ${ }^{3}$ (clothes, accessories, stuffed animals, etc.)

\begin{tabular}{|l|r|r|r|r|r|r|r|}
\hline & \multicolumn{9}{|c|}{ Model Summary } & \multicolumn{2}{c|}{ Parameter Estimates } \\
\cline { 2 - 8 } Equation & $R$ Square & $F$ & $d f 1$ & \multicolumn{1}{c|}{$d f 2$} & Sig. & \multicolumn{1}{c|}{ Constant } & \multicolumn{1}{c|}{$b 1$} \\
\hline Linear &, 028 & 19,440 & 1 & 673 &, 000 & 4,747 &,- 044 \\
Inverse &, 030 & 20,771 & 1 & 673 &, 000 & 2,622 & 25,012 \\
\hline
\end{tabular}

The independent variable is Age.

${ }^{1}$ Q5: Please describe your approach toward kawaii style and behavior? Select all that apply: a (_) I never use the word or style

b ( $($ ) I think it's childish

c ( $)$ I often use the word when describing small animals, children, etc

$\mathrm{d}$ (_) I like to behave nicely and sweetly (kawaii) toward my friends and acquaintances

e (_) I like to wear cute clothes

$\mathrm{f}$ ( $($ ) Being kawaii can be a useful strategy for getting what I need and want

$\mathrm{g}\left({ }_{-}\right.$I tend to use the word and am more friendly when observing anything kawaii

${ }^{2} \mathrm{Q} 4:$ On a scale of 1 to 5, please indicate your attitude and affection toward kawaii items (clothes, accessories, stuffed animals, etc.): 1-Dislike; 2-Dislike a little; 3-Neutral (nothing special); 4-Love to some extent; 5Really love 


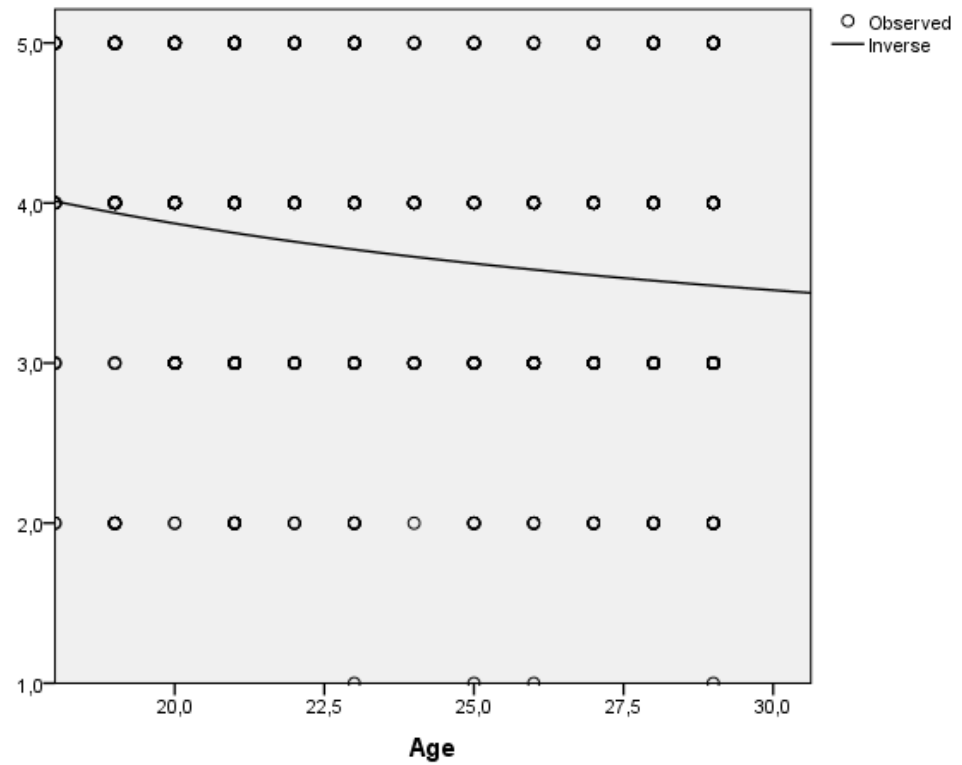

Figure 1: Attitude and affection toward kawaii items (clothes, accessories, stuffed animals, etc.)

As can be seen from the figure above, the small negative significant implies that the older a woman is, the less she will be interested in kawaii products, such as stuffed animals. As such, in terms of age, young women between the ages of 18 and 23 feel more connected to and affectionate towards kawaii items (such as clothes, stuffed animals, etc.) than mature women (aged 23-29) $\left(\left(\mathrm{Q} 7^{4}\right), \rho(675)=.107, p<.005\right)$.

Although they are more connected to kawaii items, it was found that young women defined themselves as 'less kawaii' $(\mathrm{M}=2.356$, Mean rank $=330.49, \mathrm{n}=340)$ compared to mature women $(\mathrm{M}=2.489$, Mean rank $=360.08, \mathrm{n}=350), \mathrm{U}=54398, \mathrm{p}=.039(\mathrm{z}=-2.063), \mathrm{r}=-.079$. Additionally, a difference was found between the respondents' actual age and how students and mature women see themselves. As the majority $(n=250,71.4$ per cent $)$ of mature women survey respondents were currently employed, lived independently and were self-supporting, it was expected that more of them would define themselves as adults than would the students. However, a Mann-Whitney $U$ test showed that the way young female students regard

\footnotetext{
${ }^{4}$ Q7: On a scale of 1 to 5, to what extent do you see yourself as having a kawaii persona? 1-Not kawaii at all; 2-Not very kawaii; 3-Neutral; 4-Kawaii to some extent; 5-Very kawaii
} 
themselves was significantly different to the way mature women see themselves, $U=49993.5$, $p<.003, r=-.115$, with a greater number of mature women seeing themselves as younger than their actual age $(M d n=2, n=349)$ than the students $(M d n=3, n=327)^{5}$. As can be seen, while more mature women appeared to be less interested in kawaii products, they were more likely to describe themselves as 'younger' and 'kawaii' than the students.

As a result of these findings, efforts were made to determine correlation between occupation and perceptions of kawaii products (clothes, accessories, stuffed animals, etc.). It was found that compared to other occupational groups (professional housewives, unemployed, part-time workers, and other) $\left(\chi^{2}(5)=14.386, \mathrm{p}=.013, \mathrm{n}=690\right)$, women who are company employees $(\mathrm{M}=3.806$, Mean rank $=318.06, \mathrm{n}=205)$ have as much affection for kawaii items as young female students.

For deeper understanding of company employees' positive attitudes toward kawaii items, semi-structured interviews were conducted with 12 female workers who work at TowerJazz Panasonic Semiconductor Uozu branch, Japan. All the women respondents stated they have kawaii stationery in the office such as pens, markers and stickers featuring cute characters (e.g. Disney), scissors, folders, rulers etc ${ }^{6}$.

According to Aki, a 42-year-old woman working in the customer operations section, having kawaii, small-sized stationery such as pens, calendars, and memos on her desk makes her smile and feel content, as it reminds her of her childhood (Aki, 2019, personal communication). Aki wasn't the only one who described the positive feelings and attractiveness associated with kawaii things; the majority of interview respondents gave similar answers.

Another employee, Mari, who has worked for the company for 26 years, stated that she loves kawaii that things and carries kawaii stationery featuring cute iconic characters, such as those

\footnotetext{
${ }^{5} \mathrm{Q} 2:$ On a scale of 1 to 5 , how would you describe yourself?

1-A child; 2-In a sense I feel like a child; 3-I feel like I am my age; 4-To some extent I feel like an adult; 5-An adult

${ }^{6}$ Respondents' names are incomplete to protect the respondents' confidentiality.
} 
created by Disney, with her to the office. According to her, possessing and viewing kawaii things makes her thrilled and excited (in Japanese wakuwaku). These feelings of 'excitement' were described by other employees; such as in the case of Haru who stated that having kawaii objects in the office relives tension and engenders good feelings [Tenshon ga sagaru, kimochi ga akaruku naru] (Mari, 2019, personal communication,). New employees reacted as positively as experienced employees to kawaii objects and stationery in the office. In the opinion of 18 year-old Yoko, who recently started to work in the company as a secretary, purchasing and viewing cute objects stimulates motivation, especially in the office environment (Yoko, 2019, personal communication,).

Regardless of their age and position in the company, none of the interviewees responded negatively toward having cute objects in the office. All 12 women gave positive statements, indicating that the sight of cute objects brings them happiness, excitement and pleasant feelings that sometimes reminds them their own pleasant childhood. Five of the women even presented kawaii as a 'healing tool' (in Japanese Iyasareru) for helping in challenging situations. Thus, as a healing tool, consuming kawaii in places such as the office, instead of serving as distractions, can improve workers' enthusiasm and morale.

The results of the survey and interviews show that kawaii triggers a positive response, in which the observation and consumption of kawaii products engenders beneficial effects, such as quelling anxieties, creating a sense of security and warmth, and eliciting happy feelings that bring momentary peace of mind and a reminder of one's childhood. Thus, in an environment characterized by a strict dress and behavior code, having cute products may help employees in dealing with challenging situations and even encourage them to be productive and energetic in their workplace. 


\section{Discussion: The Appeal of the Cute}

Studies of the biological roots explaining cuteness began in 1943 when Konrad Lorenz, a pioneer in the field of ethology, developed his Kindchenschema (baby/child schema) theory. According to his theory, the visual features of juvenile and young animals and infants - such as large, round eyes; a head "too large" for the body; full cheeks; and a small chin - are capable of triggering a physical and emotional response toward the observed thing (person, animal, toy, character, etc.). These infantile characteristics draw attention and cause an 'Aww' affect that motivates a positive response in humans (Buckley, 2016).

While these characteristics may be observed as 'weak', in his new book The Power of Cute, May (2019) describes cute as a powerful source of seduction that draws attention and affects the observer's response; in other word, it uses its 'weakness' as a strength to survive and 'entrap' potential consumers to buy its cute products.

But the power of cute does not come only from its weakness and vulnerability of an infant but also from its playful and fun nature. In their study, Nenkov and Scott (2014) coined a different type of cuteness named "whimsical cuteness" that does not relate to Lorenz baby-schema theory. According to them, viewing cute articles and objects, instead of empathy and compaction feelings that associates with baby-schema, bring to a fun and playful reaction from the observer. This tendency may evoke indulgent behavior and impulsive consumption rather than the careful behavior that associated with 'baby schema' cuteness (Nenkov and Scott, 2014).

In Japan there is a strong sense of value for small and immature things such as children and childlike articles that promote intimacy and remind adults of their own childhood, which, in many cases, they long to revisit (Yomota, 2006). The results of the survey emphasize the positive aspects of kawaii product consumption in engendering positive feelings, relieving stress and promoting happiness.

While kawaii products were initially produced for young women, who adore kawaii objects and 
are willing to spend large amounts of money for goods and merchandise, in recent years mature women are often regarded as the main target consumer for kawaii goods such as stationery and household goods (Decatur, 2012). This consuming of cute goods such as stationery and household associate with "whimsical cuteness" that include playfulness and amusing emotions. These feelings might explain office ladies' highly fondness toward cute ornaments and love placing them on their office desks.

Yet the current study suggests that, because students were more likely to respond positively towards kawaii goods such as teddy bears and ribbons, the world of kawaii merchandise still belongs, to some extent, to the younger generation.

In today's world, where many young people communicate with each other via social media rather than in face-to-face encounters, the consumption of cute may replace intimacy that a person's own inner circle cannot provide, to the extent that these cute items and characters become his 'shadow' family (Allison, 2004). In this sense, more than inspiring intimacy between the consumer and the consumed product, a cute object can become a 'protector' of the self that can help in expressing one's feelings and dealing with the challenging world of everyday life (Yano, 2013).

A good example of the 'healing' power of cute objects is yami-kawaii ('sick-cute' in direct translation), a relatively new sub-culture that like many other fashion statements was born in the Harajuku fashion district in Tokyo. Unlike other styles that almost exclusively focus on the cute nature of sweet pastel designs, yami-kawaii fashion combines both cute and 'sick' characteristics at the same time. This includes an integration of pastel colors with dark patterns together with negative expressions such as 'sick' (yami) and 'die' (shinu) and hospital related accessories such as bandages, masks, syringes, blood and more. More than a fashion statement, the concept of yami-kawaii expresses deep feelings of sadness and even depression, but in a cute way. This style is also connected to the term menhera, a Japanese slang word that was 
coined via the Internet and refers to mentally and unstable personas. The issue of mental health and suicide is rarely discussed in Japan, where a visit to a psychiatrist or therapist is still considered a taboo. While suicide rates have been dropping in recent years, the number is still high compared to other developed countries (according to the National Police Agency, 21,321 individuals in Japan took their lives in 2017) ${ }^{7}$.

In a video that was released on Februrary 13, 2018 by Refinery 29 the co-host explores the new yami-kawaii style in Tokyo by interviewing people who dress in this style and who believe that this style saved their lives and has helped them deal with their psychological issues. According to them, consuming cuteness helps them to cope with the harsh and strict world of Japanese society (Refinery 29, 2018). The example of the sub-culture yami-kawaii shows that consuming kawaii merchandise is widely perceived as an effective approaching that allows people to express their dark feelings in a non-confrontational way.

In view of the greater percentage of students than mature women valuing kawaii goods it was expected that the younger group would define themselves as 'young and kawaii' more than the second group of more mature women. Instead, a preponderance of mature women, who have steady jobs and incomes, reported feeling 'younger' and more 'kawaii' about themselves. These results could be interpreted as young women's attempts to convey an aura of maturity to comply with societal expectations that will allow them future professional leverage when joining a company. In his study about the 'true and false self' Winnicott (1965) describes this attempt of presenting oneself as mature as a 'false self', that comes to comply with others' expectations and to adapt to their environment. In addition, in his book, Kawaii Ron [An essay of Kawaii] (2006), Yomota states that Japanese women in their early twenties prefer to convey a more adult impression and thus prefer to be referred to using more "mature" words such as "beautiful" [kirei] and "cool" [kakoii], rather than "cute" [kawaii].

$7 \quad$ For more information, please visit the National Police Agency in
https://www.npa.go.jp/safetylife/seianki/jisatsu/H29/H29jisatsunojoukyou_01.pdf


As kawaii is originally the domain of youth, in many ways by defining themselves as kawaii and consuming related goods at an older age, adults are reminded of their own childhoods. Viewing kawaii aesthetics may inspire a romanticized memory of childhood and elicit a sense of nostalgia [natsukashi], possibly indicating a desire to 'recapture' one's youth (Morewedge 2013). The term 'nostalgia' is a compound of the Greek words nostos [return] and algos [pain, relentless longing], whereas the equivalent Japanese word, natsukashi, is an adjective used for describing feelings, sometimes sad ones, about one's past. Below are the Japanese and translated English definitions for natsukashi as presented by the Daijirin Dictionary (2006):

1. Be moved by the thought of the past [mukashi no koto ga omoi dasarete, kokoro ga hikareru].

2. A feeling floating in the mind when seeing things after a long time or thinking about the past [hisashiburi ni mitari attarishite, mukashi no koto omoidasareru jyotai da].

3. When thinking about the past and can't let it go [kako no koto ga omoi dasarete, itsu made mo hanaretakunai].

4. Cannot let go things that driven the heart. Loveable [kokoro ga hikarete tebanashi takunai. Kawairashi].

(Matsumura 2006, 1884)

Therefore, by buying kawaii products, mature consumers are able to traverse the thin lines separating youth from adulthood and to some extent to 'escape from reality through cuteness and nostalgia for childhood memories.' (Nguyen 2012, 154). In other words, consuming cuteness at a young and a more mature age creates a bridge to a fantasy realm; a momentary escape route from the high-pressured 'adult world' to a better world of cute and pink, where all unlikable and bad things vanish and are replaced by the sweet, relaxed and happy realm of the 
eternal child.

If we recognize this idea of kawaii as an escape from society, we can associate the consumption of kawaii with the Peter Pan syndrome (PPS), an emotional condition in which a person manifests an emotional regression and a desire not to grow up and take responsibility for their own actions. Peter Pan syndrome refers to individuals who reject adult responsibilities and aspire to staying young forever (Kiley, 1984). The name of the syndrome refers to the flying hero of the Matthew James Barrie novel hero, Peter Pan (1906), who resists growing up and stays forever young by staying in 'Neverland', a fictitious world where time has stopped (Kiley, 1984). As with kawaii, Peter Pan syndrome is driven by a sense of nostalgia for childhood, with a particular desire to remain childlike. To some extent, by consuming kawaii goods, young and mature women can choose to situate themselves in a 'pink bubble'. Although a correlation between the Peter Pan syndrome and kawaii does exist, the Peter Pan syndrome is considered as being only a stage in life (Kiley, 1984), whereas this study shows kawaii plays a part at various ages and life stages and in most cases provides only momentary escape from everyday life.

As can be seen, the results of the study show that both young and mature women cherish kawaii and generally have positive perceptions of it. The variance in attitudes toward kawaii merchandise between the age and status group is a proof of kawaii's authenticity, its relevance in contemporary Japan and its integral part of women's culture, for youths and adults alike.

\section{Conclusion}

The aesthetic qualities of kawaii and cuteness, which include the physical characteristics of smallness and softness, attracts the eye and stimulates positive reaction from the observer- as compassion, playfulness, and cheerfulness. Thus, kawaii and cute aesthetic has played a significant role in Japanese consumption culture, having established a strong presence that 
significantly impacts almost every segment of Japanese society. The compulsory consumption and the amount of money consumers are willing to spend on kawaii-related products make it a powerful source of revenues in the Japanese economy. Not surprisingly, companies have attempted to broaden the world of kawaii beyond young women to other age groups, including mature women who are already married and may have children, and to design products with a cute and infantile manner that brings to a good feeling in young consumers and to nostalgic feeling in older ones.

The results of the survey and interviews demonstrated that kawaii aesthetics are appreciated by both young and mature women alike, inspiring positive feelings, serving as a means to ease anxiety in and outside the office, and engendering nostalgic feelings of revisiting one's childhood. While both age and status groups voiced positive opinions of and affection towards kawaii products, there were some dissimilarities between the groups. A wide spectrum of meanings and interpretation of the term among Japanese women demonstrate kawaii's wide range of application and its relevance among all segments of women in Japan, from young to adult. This implies that with the right marketing strategy, kawaii merchandise can apply to each specific target group; from stuffed animals aimed at young women to small, pastel coloured whimsical stationery aimed at female employees. Hence, this study shows that although kawaii goods appeal due to their perceived vulnerability they can function powerfully in helping their owners deal with stress and anxiety.

We can conclude that consuming cuteness appeals to and brings positive effects to both young and mature women. For young women, it is perceived as a tool that assists in dealing with impending adulthood and helping them express their own feelings, either positive or negative. For more mature women, consuming kawaii helps in dealing with the stressful world of daily life and work and engenders nostalgic feelings about one's past, a kind of momentarily escape to a "better" world of eternal youth. 


\section{Limitations and Future Directions}

It is important to note some methodological limitations involved in this study.

- $\quad$ The first survey included participants only from three prestigious universities in Kansai: Kyoto, Doshisha and Osaka University, so the degree to which the sample represents all Japanese university female students is unclear.

- $\quad$ As the study focused on women in two age groups between 18 and 29, the responses for kawaii goods among older demographic groups is unclear.

Although this study has focused on female Japanese consumers, positive effects of the consumption of cute merchandise may be evident for other age groups and nationalities and both genders. Further research should examine the penetration of kawaii aesthetics and related merchandise among other age, gender and national groups.

\section{Declaration of conflict of interest}

The Author declares that there is no conflict of interest.

\section{Funding}

This research received no specific grant from any funding agency in the public, commercial, or not-for-profit sectors.

\section{References}

Allison A (2004) Cuteness as Japan's millennial product. In: Tobin J (ed) Pikachu's global adventure: The rise and fall of Pokémon. Durham, NC: Duke University Press, pp. 3452.

Buckley R C (2016) Aww: The emotion of perceiving cuteness. Frontiers in Psychology 7 (1740). http://doi: 10.3389/fpsyg.2016.01740 
Burdelski M and Mitsuhashi K (2010) She thinks you're kawaii: Socializing affect, gender,

Doi: 10.18910/73599

and relationships in a Japanese preschool. Language in Society 39(1): 65-93. http://doi.org/10.1017/S0047404509990650

Decatur M A (2012) Consuming cuteness in Japan: Hello Kitty, individualism and identity. Popular Anthropology Magazine 3(1): 15-18.

Endō K (2016) Kawaii no Tetsugaku sono Rekishi-teki Pāsupekutibu to Gendai-tekiligi [Cute philosophy - Its historical perspective and contemporary significance]. Jōhōshorigakkai [Information Processing Society of Japan] 57(2): 118-121.

Granot E, Alejandro T B and Russell L T (2014) A socio-marketing analysis of the concept of cute and its consumer culture implications. Journal of Consumer Culture 14(1): 66-87. http://doi: 10.1177/1469540513485274.

Kiley D (1984) Pìtā pan shindorōmu: Naze, karera wa otona ni narenai no ka. [Peter Pan syndrome: Men who have never grown up]. Tran: Keigo K. Tokyo: Shōdensha. Lieber-Milo S and Nittono H (2019a) How the Japanese Term Kawaii Is Perceived Outside of Japan: A Study in Israel. SAGE Open. https://doi.org/10.1177/2158244019869904

Lieber-Milo S and Nittono H (2019b). From a word to a commercial power - A brief introduction to the kawaii aesthetic in contemporary Japan. Innovative Research in Japanese Studies, 3, 13-32. https://doi.org/10.18910/73599

Lieber-Milo S (2017) The Macro and Micro Aspects and Effects of Kawaii. PhD Thesis, Osaka University, Japan.

Lorenz K (1943) Die angeborenen Formen möglicher Erfahrung. Zeitschrift für Tierpsychologie 5: 233-409.

Nenkov GY and Scott ML (2014) "So cute I could eat it up": Priming effects of cute products on indulgent consumption. Journal of Consumer Research 41(2): 326-

341. https://doi.org/10.1086/676581 
Nguyen A (2012) Maiden's Fashion As Eternal Becomings: Victorian Maidens and Sugar Sweet Cuties Donning Japanese Street Fashion in Japan and North America. PhD Thesis, The University of Western Ontario, Canada.

Nittono H (2016) The two-layer model of "Kawaii”: A behavioral science framework for understanding kawaii and cuteness. East Asian Journal of Popular Culture Special Issue "Cute Studies" 2(1): 79-98.

Nittono H (2019a). Kawaii no chikara- Jikken de saguru sono shinri [The power of kawaii: A view from experimental psychology]. Kyoto: Dojin.

Nittono H (2019b) Meaning of 'kawaii' from a psychological perspective. In: Ohkura M (ed) Kawaii engineering measurements, evaluations, and applications of attractiveness. Singapore: Springer, pp. 141-146.

Nikkei Business Publications. (2018-2019). Daigaku burando rankingu [The brand rankings of Japanese universities]. Japan: Nikkei Business Publications Consulting, Inc. Retrieved August 20, 2019, from https://consult.nikkeibp.co.jp/info/news/2018/1128ubj_4/

May S (2019) The power of cute. Princeton: Princeton University Press.

Matsumura A, ed (2006) Daijirin (3rd ed.). Tokyo: Sanseido.

Monden M (2015) Japanese fashion cultures: Dress and gender in contemporary Japan. London: Bloomsbury.

Morewedge C K (2013) It was a most unusual time: How memory bias engenders nostalgic preferences. Journal of Behavioral Decision Making 26(4): 319-326.

Ohkura M (2019) Kawaii engineering. In: Ohkura M (ed) Kawaii engineering measurements, evaluations, and applications of attractiveness. Singapore: Springer, pp. 3-14.

Refinery 29 (2018) The Dark Side Of Harajuku You Haven't Seen Yet. Available at: https://www.refinery29.com/en-us/yami-kawaii-fashion-harajuku-style-dark (accessed 5 July 2019). 
Sei Shōnagon (2011) The pillow book of Sei Shōnagon, the diary of a courtesan in tenth century Japan. Trans: Waley A. Singapore: Tuttle Publishing (Original work published 1002; original translation published 1928).

Winnicott D W (1965) Ego distortion in terms of true and false self. In: Winnicott DW (ed) The maturational process and the facilitating environment: Studies in the theory of emotional development, edited by. New York, NY: International Universities Press, pp. $140-152$.

Yano C R (2013) Pink globalization: Hello Kitty’s trek across the Pacific. Durham: Duke University Press.

Yomota I (2006) Kawaii ron [An essay on kawaii]. Tokyo: Chikuma Shinsho. 